\title{
Incidence and Risk Factors of Wound Infection in Women Who Underwent Cesarean Section in 2014 at King Abdulaziz Medical City, Jeddah
}

\author{
Roaa Gadeer ${ }^{1}$, Nada Y. Baatiah ${ }^{2}$, Nourah Alageel $^{3}$, Mohammed Khaled ${ }^{4}$ \\ 1. Department of Obstetrics and Gynecology, King Faisal Specialist Hospital \& Research Centre, Jeddah, SAU 2. Clinical \\ Nutrition, King Saud Bin Abdulaziz University for Health Sciences, Jeddah, SAU 3. Medicine, King Saud Bin Abdulaziz \\ University for Health Sciences, Jeddah, SAU 4. Consultant Obstetrics and Gynecology, The Ministry of National Guard \\ Health Affairs, Jeddah, SAU
}

Corresponding author: Nada Y. Baatiah, nadayasser1027@gmail.com

\section{Abstract \\ Introduction}

Cesarean section $(\mathrm{C} / \mathrm{S})$ is considered one of the most commonly performed procedures among women. The maternal morbidity due to infection post-C/S reaches eight-fold higher than that of vaginal delivery. Our aim is to identify the incidence and risk factors of surgical site infection (SSI) among patients at King Abdul Aziz Medical City (KAMC), Jeddah, Saudi Arabia, in order to develop a strong strategy to reduce its occurrence.

\section{Methods}

This retrospective cohort study was conducted at KAMC, Jeddah. The study included a total of 387 women who underwent cesarean sections from January 2014 to December 2014. The data were collected consecutively by reviewing medical records of pregnant patients who underwent elective or emergency C/S. The risk factors studied included age, presence of underlying diseases, BMI, hemoglobin level, prophylactic antibiotics, pre-labor rupture of membrane, duration of induction of labor, type of $\mathrm{C} / \mathrm{S}$, type of uterine incision, duration of operation, type of anesthesia, estimated blood loss, type of organism, and the duration of hospital stay postoperatively.

\section{Results}

The incidence rate of wound infections (WI) was 3.4\% (13/387). The mean age score was $31.1 \pm 5.6$ years, and the mean score of BMI was $32.7 \pm 6.2$, where the majority were obese $(255,65.9 \%)$. More than half of the participants (205, 53.0\%) had elective C/S, with mean hospitalization duration $2.5 \pm 1.3$ days, and operation duration mean score $59.5 \pm 22.0$ minutes. The majority $(378,97.7 \%)$ received antibiotics before the operation, where cefazolin was the main antibiotic (376, 97.2\%). Only 38 (10\%) cases had intra-operative complications, where the main complication was postpartum hemorrhage $(18,44.0 \%)$. The majority of WI were superficial (11 cases), the main organism was E. coli in four (36.4\%) cases, followed by Staphylococcus aureus in three (27.3\%) cases. There was a significant association between WI post-C/S and BMI, type of uterine incision, and induction of labor ( $\mathrm{P}=006, \mathrm{P}=0.003$, respectively).

Review began $11 / 19 / 2020$ Review ended 12/13/2020 Published 12/19/2020

() Copyright 2020 Gadeer et al. This is an open access article distributed under the terms of the Creative Commons Attribution License CC-BY 4.0., which permits unrestricted use, distribution, and reproduction in any medium, provided the original author and source are credited.

\section{Conclusions}

This study showed that WI post-C/S is associated with high BMI, prolonged induction of labor, and Pfannenstiel incision. Reducing the rate of SSI will help to reduce its morbidity by identifying the risk factors pre-pregnancy and encouraging the implementation of preconception counseling clinics and antenatal classes to educate and increase awareness among patients.

Categories: Obstetrics/Gynecology, Infectious Disease

Keywords: cesarean section, wound infections, emergency and elective cesarean, surgical site infection

\section{Introduction}

Cesarean section $(\mathrm{C} / \mathrm{S})$ is considered one of the most commonly performed procedure among women [1]. The $\mathrm{C} / \mathrm{S}$ rate has increased over the years, and the international rate reached approximately $15 \%$ [2]. A study showed that the maternal morbidity due to infection post- $\mathrm{C} / \mathrm{S}$ reached eight-fold higher than vaginal delivery [3]. Also, studies indicate that surgical site infection (SSI) post-C/S has the highest number among infections [4,5]. According to the Centers for Disease Control and Prevention (CDC), SSI refers to any infections occurring within 30 days after surgical operation [6]. SSIs are common surgical complications among patients who delivered with C/S. A study at the university hospital in Jeddah reported an SSI rate of $19 \%$ after cesarean delivery [7]. As a result of having SSI, the duration of the hospital stay and the rate of hospital re-admission will increase, also the rate of mortality and morbidity will become higher [8]. According to the CDC, SSI has been classified into subgroups; the first subgroup is superficial incisional SSI, which involves only skin or subcutaneous tissue. The second subgroup is deep incisional SSI, which involves deep soft tissues of the incision and organ. The last subgroup is space SSI that involves any part of the anatomy [9]. 
There are many risk factors for SSI post-C/S. They can be divided into intrinsic (patient-related) and extrinsic (management and care-related) risk factors. An example of the intrinsic factor is the age of the patient; pregnant patients who are 35 and above are at a higher chance to develop SSI post-C/S [10]. Another risk factor is obesity; pregnant patients with a high body mass index (BMI) (25 and above) have a higher risk for SSI after C/S [11]. Also, pregnant patients with other co-morbidities such as diabetes mellitus, anemia, and hypertension have more risk to have SSI post-C/S [12]. Regarding the extrinsic factors, one of the risk factors is the inappropriate use of antibiotics. Patients who received an inappropriate type of antibiotics or received the dose at an inappropriate time had an increased risk of SSI post-C/S [13]. The second risk factor is the number of vaginal or anal examinations. If the patient had multiple vaginal or anal examinations, then the patient is at higher risk to have SSI after C/S. Another risk factor is blood loss; pregnant patients who had excessive blood loss during the surgery had a higher risk to have SSI post-C/S [11]. Also, operative time is one of the risk factors of having SSI post-C/S. If the duration of the operation took more than one hour, the patients will be at more risk to have SSI [11]. Patients who had prolonged labor or had pre-labor rupture of the membrane more than 24 hours are at higher risk to develop SSI [8]. Moreover, emergency C/S is another risk factor of SSI. The patients who underwent emergency C/S are at high risk to have SSI [8]. Also, the character and bacteriological study of wound discharge are considered as a risk factor of SSI. By wound swab, studies found that most of the patients their infection occurred by Staphylococcus [8]. Another important risk factor is the type of incision. Many studies found that Pfannenstiel (transverse) incision has more risk to develop SSI post-C/S [10]. Also, if the anesthesia was spinal, the risk to develop SSI after C/S is higher [14]. Finally, the skill level of the surgeon is considered a risk factor of having SSI post-C/S. If the surgeon is a junior, the risk to have SSI will be higher [15].

There are a lot of studies that report the incidence and risk factors of wound infection (WI) in women who underwent C/S internationally, but we could not find any study that talks about risk factors of SSI post-C/S in Saudi Arabia. Also, there is only one old study, which mentioned the incidence of SSI post-C/S at King Abdul-Aziz hospital in Jeddah in 1992 [7].

The study will increase the public data available regarding the risk factors of WI in women who undergo C/S in Saudi Arabia. We aim to identify the incidence and the significant risk factors of SSI during 2014 among patients at King Abdulaziz Medical City (KAMC), Jeddah, in order to help in developing strong strategies to reduce its occurrence.

\section{Materials And Methods}

In this retrospective cohort study, the data was collected consecutively by reviewing medical records of pregnant patients who underwent elective or emergency C/S at KAMC, Jeddah in the study period from January 2014 till December 2014. Three hundred eighty-seven cases were reviewed to compare the incidence of WI among women who underwent emergency C/S with those who underwent elective $\mathrm{C} / \mathrm{S}$ in all ages. The study was approved by King Abdullah International Medical Research Center (IRBC/1417/17).

The data were collected by research team members through a standard data collection tool design for this study. Patients' demographics, presence of underlying diseases, preoperative, intra-operative, and postoperative data were compared among these patients. The preoperative data include hemoglobin level and prophylactic antibiotics. Intra-operative data include the type of uterine incision, duration of the operation, type of anesthesia, and estimated blood loss. Postoperative data include the duration of hospital stay postoperatively, SSI, and its classification. Completed data collection sheet transferred to excel sheet in a secured computer. The data encrypted and stored in a locked file accessed only by the primary investigator. Data have been reviewed and cleaned before analysis.

As a policy of the hospital, all patients who underwent C/S at KAMC should receive prophylaxis antibiotics of 1 gram, intravenous cefazolin, pre-operational, unless the patient is allergic to it (clindamycin or vancomycin will be given). The scrubbing used to clean the patient is standardized, using chlorhexidine and the scrubbing used by the doctors is chlorhexidine digluconate $4 \%$.

SSI was classified according to the CDC classification: superficial infection that involves only skin and subcutaneous tissue, deep infection that involves deep tissue (fascial and muscle layers), and organ/space infection that involves any part of the body deeper than the fascial/muscle layers. Moreover, the World Health Organization (WHO) classification was used for BMI categories: underweight $<18.5$, normal range (18.5-24.9), overweight (25-29.9), obese $>=30$.

Statistical analysis was performed using Statistical Package for Social Sciences (SPSS) version 22 (IBM Corp., Armonk, NY, USA). Qualitative variables were presented using frequencies and percentages while quantitative variables were presented by the mean and standard deviation. To assess the significance of the relationship between the risk factors variables, the type of $\mathrm{C} / \mathrm{S}$ (elective or emergency), and the development of the outcome, which is SSI, we applied a Chi-square test, two-sided, with the level of a significant set at 0.05 . Chi-square test for categorical data and multivariable regression models performed in order to identify factors associated with SSI post-C/S.

\section{Results}

This study enrolled $387 \mathrm{C} / \mathrm{S}$ performed in the study period from January 2014 to December 2014. The incidence rate of WI was $3.4 \%$ (13/387). The mean age score was $31.1 \pm 5.6$ years ranging from 19 to 51 years. The mean score of BMI was $32.7 \pm 6.2$, where the majority were obese $(255,65.9 \%)$ or overweight $(97,25.1 \%)$. 


\section{Cureus}

A quarter of the cases were diabetic patients (25.3\%), out of which 90 (23.2\%) cases had gestational diabetes. The median scores of gravidity, parity, and previous C/S were $3 \pm 3,2 \pm 2$, and $2 \pm 2$ respectively.

The results showed that the mean score of gestational age was 38.5 2.2 weeks, 19 (4.9\%) cases had multiple pregnancies, and 80 (20.7\%) had pre rupture of membranes (PROM). Also, 68 (17.6\%) patients had meconium-stained liquor, and only three $(0.8 \%)$ had chorioamnionitis. More than half of the cases (205, $53 \%$ ) had elective $\mathrm{C} / \mathrm{S}$, with mean hospitalization score $2.5 \pm 1.3$ days, and operation duration mean score $59.5 \pm 22.0$ minutes. The transverse incision was the type of uterine incision in 383 (99.0\%) of the cases. The mean level of hemoglobin before the operation was $11.5 \pm 1.3 \mathrm{~g} / \mathrm{dl}$ and the average estimated blood loss was $815 \pm 382 \mathrm{ml}$. The majority of patients $(378,97.7 \%)$ received antibiotics before the operation, where cefazolin was the main used $(376,97.2 \%)$, and the other two cases received a combination of antibiotics. Only 38 (10\%) cases had intra-operative complications, where the main complication was postpartum hemorrhage (18, $44.0 \%$ ) followed by extension (11, 26.8\%), then bowel injury (five, 12.2\%). Group B strep tests (GBS) status were positive in 49 (12.7\%) and negative in 112 (29\%). Two-thirds of the cases (255, 65.9\%) received spinal anesthesia, followed by epidural $(72,18.6 \%)$, then general $(58,15.0 \%)$. Moreover, 70 (18.1\%) reported induction of labor, and only two (0.5\%) cases received immunosuppressive medication. The additional pregnancy information is presented in Table 1 .

\begin{tabular}{|c|c|c|}
\hline Variable & $\mathbf{N}$ & $\%$ \\
\hline \multicolumn{3}{|l|}{ Experience multiple pregnancies: } \\
\hline Yes & 19 & 4.9 \\
\hline No & 368 & 95.1 \\
\hline \multicolumn{3}{|l|}{ Having rupture of membrane: } \\
\hline Yes & 80 & 20.7 \\
\hline No & 307 & 79.3 \\
\hline \multicolumn{3}{|l|}{ Having meconium-stained liquor: } \\
\hline Yes & 68 & 17.6 \\
\hline No & 319 & 82.4 \\
\hline \multicolumn{3}{|l|}{ Chorioamnionitis: } \\
\hline Yes & 3 & .8 \\
\hline No & 384 & 99.2 \\
\hline \multicolumn{3}{|l|}{ Type of caesarean section: } \\
\hline Emergency caesarean section & 182 & 47.0 \\
\hline Elective caesarean section & 205 & 53.0 \\
\hline \multicolumn{3}{|l|}{ Type of uterine incision: } \\
\hline Classical & 4 & 1.0 \\
\hline Transverse & 383 & 99.0 \\
\hline \multicolumn{3}{|l|}{ Antibiotic received pre-operation: } \\
\hline Yes & 378 & 97.7 \\
\hline No & 9 & 2.3 \\
\hline \multicolumn{3}{|l|}{ Type of antibiotic received } \\
\hline Not applicable & 9 & 2.3 \\
\hline Cefazolin & 376 & 97.2 \\
\hline Ampicillin, Gentamysin, Metramideole & 1 & 0.3 \\
\hline Gentamysin,Clindamycin & 1 & 0.3 \\
\hline \multicolumn{3}{|l|}{ Having intr-aoperative complications: } \\
\hline Yes & 38 & 10.0 \\
\hline No & 349 & 90.0 \\
\hline What is the complication? & & \\
\hline
\end{tabular}




\section{Cureus}

\begin{tabular}{|c|c|c|}
\hline Ureter ligation & 1 & 2.4 \\
\hline Bowel injury & 5 & 12.2 \\
\hline Extension & 11 & 26.8 \\
\hline PPH & 18 & 44.0 \\
\hline Scar dehiscence & 1 & 2.4 \\
\hline Partial Placenta accreta & 1 & 2.4 \\
\hline Placenta accreta & 1 & 2.4 \\
\hline Bilateral internal illiac atery ligation & 1 & 2.4 \\
\hline Ureteric Injury & 2 & 4.8 \\
\hline \multicolumn{3}{|l|}{ GBS status: } \\
\hline Positive & 49 & 12.7 \\
\hline Negative & 112 & 29.0 \\
\hline Unknown & 226 & 58.3 \\
\hline \multicolumn{3}{|l|}{ Type of anesthesia: } \\
\hline Epidural & 72 & 18.6 \\
\hline Spinal & 255 & 65.9 \\
\hline General & 58 & 15.0 \\
\hline Unknown & 2 & 0.5 \\
\hline \multicolumn{3}{|l|}{ Level of training (Surgeon): } \\
\hline Seniors & 329 & 85.0 \\
\hline Residents & 54 & 14.0 \\
\hline \multicolumn{3}{|l|}{ Induction of labor: } \\
\hline Yes & 70 & 18.1 \\
\hline No & 317 & 81.9 \\
\hline \multicolumn{3}{|l|}{ taking immunosuppressive medications: } \\
\hline Yes & 2 & .5 \\
\hline No & 385 & 99.5 \\
\hline \multicolumn{3}{|l|}{ Name of immunosuppressive used } \\
\hline Hydrocortisone \& Prednisolon & 1 & 50 \\
\hline Prednisolon , Hydrocortisone , IVIG & 1 & 50 \\
\hline Variables & Mean \pm SD & Range (min-max) \\
\hline Gestational age: & $38.5 \pm 2.2$ weeks & $(29-42)$ \\
\hline $\mathrm{C} / \mathrm{S}$ Duration of hospital stay after $\mathrm{C} / \mathrm{S}$ : & $2.5 \pm 1.3$ days & $(1-21)$ \\
\hline Preoperative hemoglobin level: & $11.5 \pm 1.3 \mathrm{~g} / \mathrm{dl}$ & $(7.2-15.3)$ \\
\hline Duration of the surgery: & $59.5 \pm 22.0$ minutes & $(17-240)$ \\
\hline Blood loss: & $815 \pm 382 \mathrm{ml}$ & $(300-4500)$ \\
\hline
\end{tabular}

\section{TABLE 1: Current pregnancy information}

C/S: Cesarean section; GBS: group B strep; PPH: postpartum hemorrhage; IVIG: intravenous immunoglobulin

Only 13 (3.4\%) cases suffered from WI, where the majority of WI were superficial (11 cases). The main organism was Escherichia coli in four (36.4\%) cases, followed by Staphylococcus aureus in three (27.3\%) cases. Only two $(0.5 \%)$ cases required readmission due to WI, with mean length of stay $7.5 \pm 2.2$ days, as can be seen 


\section{Cureus}

in Table 2.

\begin{tabular}{|c|c|c|}
\hline Variable & $\mathbf{N}$ & $\%$ \\
\hline \multicolumn{3}{|c|}{ Developing wound infection: } \\
\hline Yes & 13 & 3.4 \\
\hline No & 374 & 96.6 \\
\hline \multicolumn{3}{|c|}{ Classification of wound infection: } \\
\hline Superficial & 11 & 84.6 \\
\hline Deep & 1 & 7.7 \\
\hline Unknown & 1 & 7.7 \\
\hline \multicolumn{3}{|l|}{ Type of the organism: } \\
\hline Staph. Aureus & 3 & 27.3 \\
\hline Unknown & 3 & 27.3 \\
\hline E.coli & 4 & 36.4 \\
\hline Proteus mirabilis & 1 & 9.1 \\
\hline Enterococcus faecalis & 1 & 9.1 \\
\hline \multicolumn{3}{|c|}{ Readmission due to wound infection: } \\
\hline Yes & 2 & 0.5 \\
\hline No & 385 & 99.5 \\
\hline \multicolumn{3}{|c|}{ Complication of wound infection: } \\
\hline Yes & 2 & 15.4 \\
\hline No & 11 & 84.7 \\
\hline
\end{tabular}

TABLE 2: Post Cesarean section (C/S) and wound infection data

The results in this study revealed a significant association between WI post-C/S and some risk factors include BMI, type of uterine incision, and induction of labor, as illustrated in Table 3. 


\section{Cureus}

\begin{tabular}{|c|c|c|c|}
\hline Variables & wound infections (Yes) N $(\%)$ or Mean \pm SD & wound infections (No) N (\%) or Mean \pm SD & P-value \\
\hline BMI: & & & 0.05 \\
\hline Underweight & 0 & $4(1.1)$ & \\
\hline Normal & 0 & $31(8.2)$ & \\
\hline Overweight & $\left.1(1 .)^{1}\right)$ & $96(25)$. & \\
\hline Obesity & $12(92.3)$ & $243(65.0)$ & \\
\hline Meconium: & & & 0.18 \\
\hline Yes & $4(30.8)$ & $64(1 / .1)$ & \\
\hline No & $9(69.2)$ & $310(82.9)$ & \\
\hline Caesarean section type: & & & 0.41 \\
\hline Emergency & $7(53.8)$ & $175(46.8)$ & \\
\hline Elective & $6(46.2)$ & $199(53.2)$ & \\
\hline Uterine incision: & & & $0.006^{x}$ \\
\hline Yes & $2(15.4)$ & $2(0.5)$ & \\
\hline No & $11(84.6)$ & $372(99.5)$ & \\
\hline Recelved preoperative antiolotic: & & & 0.24 \\
\hline Yes & $12(92.3)$ & $366(98.1)$ & \\
\hline No & $1(7.7)$ & $7(1.9)$ & \\
\hline Developed intraoperative complications: & & & 0.53 \\
\hline Yes & $2(15.4)$ & $36(9.7)$ & \\
\hline No & $11(84.6)$ & $337(90.3)$ & \\
\hline Level of training of the surgeon: & & & 0.43 \\
\hline Senior & $12(92.3)$ & $317(85.7)$ & \\
\hline Resident & $1(7.7)$ & $53(14.3)$ & \\
\hline Underlying diseases: & & & 0.28 \\
\hline GDM & $2(33.3)$ & $88(62.0)$ & \\
\hline DM & $1(16.7)$ & $7(4.9)$ & \\
\hline Other & $3(50.0)$ & $47(33.1)$ & \\
\hline Induction of labor: & & & $0.003^{\star}$ \\
\hline Yes & $7(53.8)$ & $64(17.1)$ & \\
\hline No & $6(46.2)$ & $310(82.9)$ & \\
\hline Hospitalization duration: & Mean \pm SD $3.1 \pm 1.1$ & Mean \pm SD 2.5 \pm 1.1 & 0.10 \\
\hline Operation duration: & Mean \pm SD $61.8 \pm 21.8$ & Mean \pm SD 59.4 \pm 22.5 & 0.70 \\
\hline
\end{tabular}

TABLE 3: Relation between wound infectious and several risk factors:

GDM: gestational diabetes mellitus; DM: diabetes mellitus

\section{Discussion}

The findings of this study are in agreement with the results in some previous studies. Regarding the incidence of WI, Schneid-Kofman retrospectively analyzed 19,416 patients who had cesarean delivery and found that 726 (3.7\%) patients developed WI. Comparing the previous study to our results, the rate of WI post-C/S is $3.4 \%[16]$.

Regarding the risk factors, we found some risk factors that associate with SSI post-C/S and have similar 
findings with other studies. One of the most significant risk factors is obesity. In a study conducted in China, a total of 13,798 women underwent C/S and the results showed that $96(0.7 \%)$ developed SSI and only 73 cases from the 96 had complete data on risk factors, out of which more than half of them were obese (67.1\%) [11]. This finding is similar to our study, which found that the risk of SSI was highest among patients who have higher BMI in the obese range. Moreover, from the data obtained in this study, the mean BMI was 32 with a range from 18-62, which is well above the standard known. This is in itself merits further research. There are various mechanisms that make obesity a very serious risk factor for SSI. In the operating room, obese patients present technical challenges that often result in increased procedure time and resulted in many complications. As a result, the redundant skin over the wound site, sometimes poor hygiene, and poor penetration of antibiotics in the adipose tissue attributed to this associated risk.

Another risk factor is the duration of the induction of labor, which was significantly associated with SSI. In the current study, 53.8\% of infected mothers also had a long induction of labor. Likewise, in a cross-sectional observational study aimed to assess the risk factors of incisional SSI, 35\% of the women who had SSI post$\mathrm{C} / \mathrm{S}$ had prolonged labor [8].

Regarding the bacteriological study, according to the National Nosocomial Infections Surveillance System, Staphylococcus aureus accounts for approximately $20 \%$ of nosocomial Infections. Furthermore, it is the most common organism isolated from SSI [17]. However, in our study, Escherichia coli was isolated in four cases out of 13. Although higher than other studies, the small number may falsely give this impression.

Another important risk factor that can lead to SSI post-C/S is the level of training. The experience of the consultants and registrars usually protects against WI, but in our study the results were different. We observed that most of the cases of WI were done by seniors, either consultants or registrars. This can be explained by the high-risk cases with high BMI, severe pre-eclampsia, and the second stage of labor usually have been done by the seniors. As a result, that may contribute to a high rate of wound infection in this group.

Regarding the type of incision and its impact in causing SSI post-C/S, Molla retrospectively analyzed 334 women who underwent C/S and had SSI. The study found that 291 (87.1\%) of women who had SSI post-C/S had Pfannenstiel incision [10]. Our finding was consistent with this study that $84.6 \%$ of women who had C/S and Pfannenstiel incision also found to have SSI. Moreover, another risk factor of SSI post-C/S is the type of anesthesia. Jasim retrospectively analyzed 400 women who underwent $\mathrm{C} / \mathrm{S}$ and found that 75 (18.8\%) had SSI; 58 out of 75 (77.3\%) had spinal anesthesia [14]. Our study shows similar findings, that spinal anesthesia is considered a risk of devolving SSI post-C/S.

For the other risk factors, although by regression analysis we could not find a significant association between SSI and the other proposed risk factors, which are inappropriate use of prophylactic antibiotics, level of training, numbers of vaginal or oral examinations, excessive blood loss (need further analysis), operation time, duration of hospital stay postoperatively, pre rupture of membrane, emergency C/S, age, and having other comorbidities, but this could be because of the small sample size. Accordingly, multicenter studies are needed.

\section{Conclusions}

This study showed that WI post-C/S is associated with high BMI, prolonged induction of labor, and Pfannenstiel incision.

Although the policy of the hospital states clearly that all patients going to the operative room should receive antibiotics (cefazolin $1 \mathrm{~g}$, IV, stat, on-call to operation room unless allergic they will receive clindamycin or vancomycin), it seems that some cases did not receive it and no reason was given. We recommend the infectious and prevention control administrative to emphasize strictly applying this policy.

Reducing the rate of SSI will help to reduce morbidity by identifying the risk factors pre-pregnancy and encouraging implementing preconception counseling clinic and antenatal classes to educate and increase awareness among patients.

\section{Additional Information \\ Disclosures}

Human subjects: Consent was obtained by all participants in this study. King Abdullah International Medical Research Center (KAIMRC) issued approval IRBC/1417/17. Animal subjects: All authors have confirmed that this study did not involve animal subjects or tissue. Conflicts of interest: In compliance with the ICMJE uniform disclosure form, all authors declare the following: Payment/services info: All authors have declared that no financial support was received from any organization for the submitted work. Financial relationships: All authors have declared that they have no financial relationships at present or within the previous three years with any organizations that might have an interest in the submitted work. Other relationships: All authors have declared that there are no other relationships or activities that could appear to have influenced the submitted work.

\section{Acknowledgements}

The research team would like to express their very great appreciation to Dr. Mohamed Ashmawi and Dr. 


\section{References}

1. Betrán AP, Merialdi M, Lauer JA, Bing-Shun W, Thomas J, Van Look P, Wagner M: Rates of caesarean section: analysis of global, regional and national estimates. Paediatr Perinat Epidemiol. 2007, 21:98-113. 10.1111/j.1365-3016.2007.00786.x

2. Chalmers B: WHO appropriate technology for birth revisited. BJOG. 1992, 9:709-10. 10.1111/j.14710528.1992.tb13867.x

3. Häger RM, Daltveit AK, Hofoss D, Nilsen ST, Kolaas T, Qian P, Henriksen T: Complications of cesarean deliveries: rates and risk factors. Am J Obstet Gynecol MFM. 2004, 190:428-34. 10.1016/j.ajog.2003.08.037

4. Horan TC, Gaynes RP, Martone WJ, Jarvis WR, Emori TG: CDC definitions of nosocomial surgical site infections, 1992: a modification of CDC definitions of surgical wound infections. Infect Control Hosp Epidemiol. 1992, 13:606-608. 10.1017/s0195941700015241

5. Olsen MA, Butler AM, Willers DM, Gross GA, Hamilton BH, Fraser VJ: Attributable costs of surgical site infection and endometritis after low transverse cesarean delivery. Infect Control Hosp Epidemiol. 2010, 31:276-282. 10.1086/650755

6. Consensus paper on the surveillance of surgical wound infections . Infect Control Hosp Epidemiol. 1992, 13:599-605. 10.1086/646435

7. Eltahawy AT, Mokhtar AA, Khalaf RM, Bahnassy AA: Postoperative wound infection at a university hospital in Jeddah, Saudi Arabia. J Hosp Infect. 1992, 21:79-83. 10.1016/0195-6701(92)90156-g

8. Shikha SS, Latif T, Moshin M, et al.: Evaluation of surgical site infection among post cesarean patients in Mymensingh Medical College Hospital. Mymensingh Med J. 2018, 27:480-486. https://europepmc.org/article/med/30141435.

9. Surgical Site Infection (SSI) Event. (2015). Accessed: April 15 2018: https://apic.org/Resource_TinyMceFileManager/Academy/ASC_101_resources/Surveillance_NHSN/NHSN_9pscSSIcurrent_jan2

10. Molla M, Temesgen K, Seyoum T, Melkamu M: Surgical site infection and associated factors among women underwent cesarean delivery in Debretabor General Hospital, Northwest Ethiopia: hospital based cross sectional study. BMC Pregnancy Childbirth. 2019, 19:317. 10.1186/s12884-019-2442-0

11. Gong SP, Guo HX, Zhou HZ, Chen L, Yu YH: Morbidity and risk factors for surgical site infection following cesarean section in Guangdong Province, China. J Obstet Gynaecol Res. 2012, 38:509-515. 10.1111/j.14470756.2011.01746.x

12. Zejnullahu VA, Isjanovska R, Sejfija Z, Zejnullahu VA: Surgical site infections after cesarean sections at the University Clinical Center of Kosovo: rates, microbiological profile and risk factors. BMC Infect Dis. 2019, 19:10.1186/s12879-019-4383-7

13. Kim KH, Park CS, Chang JH, et al.: Association between prophylactic antibiotic use and surgical site infection based on quality assessment data in Korea. J Prev Med Public Health. 2010, 43:235. 10.3961/jpmph.2010.43.3.235

14. Jasim HH, Sulaiman SA, Khan AH, Dawood OT, Abdulameer AH: Incidence and risk factors of surgical site infection among patients undergoing cesarean section. Clin Med Insights Ther. 2017, 9:10.1177/1179559x17725273

15. Rose Af, Fekad B, Moore JN, Graham WJ: Post-caesarean section surgical site infections: a retrospective audit and case note review at an Ethiopian referral hospital. Obstet Gynecol Rep. 2018, 2:6. 10.15761/ogr.1000126

16. Schneid-Kofman N, Sheinerr E, Levy A. Holcberg G: Risk factors for wound infection following cesarean deliveries. Int J Gynaecol Obstet. 2005, 90:10-5. 10.1016/j.ijgo.2005.03.020

17. NNIS System: National Nosocomial Infections Surveillance (NNIS) System Report, data summary from January 1992 through June 2004, issued October 2004. Am J Infect Control. 2004, 32:470-485. 10.1016/j.ajic.2004.10.001 